\title{
Stability and change of the quality of working life in restructuring municipalities
}

\author{
Tuula Heiskanen ${ }^{1}$, Phone: +358-50-3186082 Email: tuula.heiskanen@uta.fi \\ Esa Jokinen ${ }^{1}$
}

\begin{abstract}
Local government in Finland has undergone considerable restructuring since 2005 as a number of new larger municipalities (mergers) and partnership areas between social and health sector service producers have been formed. Employees and the quality of their working life have not been among the main issues in this government-driven restructuring process. The article focuses on the observed changes in the quality of working life in Finnish municipalities. The data consist of two comprehensive surveys carried out in 2009 ( $\mathrm{N}=$ $3,710)$ and $2011(\mathrm{~N}=4,618)$ for employees in the social and health sector and the education sector, and in 2011 also for employees in the administration sector, and of comparison data from the years 1995, 1999 and 2003. Quality of working life (QWL) consists of five sum variables: open ways to solve work conflicts, work influence, supervisory work, social openness at workplace, and intrinsic rewards of work. The measures proved to reflect in context-specific ways situations and conditions of work. The results imply that QWL is quite a slowly changing phenomenon, which is revealed here through a long-term research period and statistical comparisons. On the level of daily work, the wide-scale reform seemed more incremental than radical. As a positive sign, it is noteworthy that the intrinsic rewards of work have remained on a relatively high level through the years. There are some cases in which QWL has changed more radically. It is obvious that the reform context has increased awareness of human resource issues in these cases, which is visible in the improved QWL. It is also possible that the improvement in the supervisory role as reflected in increased satisfaction with supervisors and the relatively high level of social capital in most of the municipalities have played a buffering role against the confusion and strains related to the reform.
\end{abstract}

Keywords: Local government reform, Quality of working life, Restructuring, 


\section{Services}

\section{Introduction}

Local government reforms are currently on the agenda in many countries. The reasons for generating some change in the functioning of their local governments are quite often the same. In fact, the aim of improving the performance of the operating local units of the public sector is generally driven by the expectation to deliver and produce services in cost-effective ways (Denters and Rose 2005; Dollery et al. 2008). In many countries, this need for financial considerations is coupled with the need to rethink the service requirements of aging populations (Moisio 2012: 3; Rose and Ståhlberg 2005: 99). In justifying and evaluating the reforms, fiscal problems and citizens' desire for both good services and accountable local government tend to create a tension-filled bundle of issues to be solved. However, the personnel's conditions and viewpoints are quite rarely taken into robust consideration and evaluation in the reforms. This follows partly from the fact that although broad governmental reforms may imply some changes in human resource management systems as well, most often these have not been the central focus of the reform (Ingraham 2007: 521). This study focuses on the personnel by employing the concept of Quality of Working Life (QWL), which provides indicators for measuring and evaluating human conditions in work.

The quality of working life is a significant social issue for both individual organizations and societies at large. Social scientists and psychologists have theorized and studied the aspects related to it for decades (Martel and Dupuis 2006, Sippola 2011, Sirgy et al. 2001), and possible changes in the world of work have been on the political agendas of nation-states and international organizations (Green 2006). Both the questions of adequate measuring (Levine et al. 1984, Martel and Dupuis 2006, Sippola 2011, Walton 1975) and the indications of change in the quality of working life have received attention (Fifth European Working Conditions Survey 2010). Still, the number of studies that would allow an examination of the development trends in contextualized ways is limited. By the term 'contextualized' we refer here to the availability of information that 
makes it possible to tie employees' experiences to organizational and other changes in the conditions of work.

The quality of working life will have special significance in the forthcoming years. Municipalities have to compete for skilled workforce with work providers in other sectors. In a number of countries, worries have been expressed that the image of public service might be eroding (Colley et al. 2012: 509). In Finland, the attraction of work and availability of skilled workforce present challenges that have to be met with special care for two reasons. First, municipalities have broad service provision responsibilities in health and social care as well as in education. Second, the demographic structure of the population is changing rapidly, which sets special demands on services offered for aging citizens. At the same time, the number of retirements among the municipal workers is growing (e.g. Halmeenmäki 2010).

This study deals with the development trends of the quality of working life in municipalities in Finland. The main focus is on the present five-year period, during which major structural changes have been made in local government in Finland. These reforms aim to ensure the future quality and availability of services for which the local authorities are responsible in a changing operating environment caused, among other things, by the aging population and dwindling fiscal resources. The results will be reflected against prior knowledge of the longer-term trends in the quality of working life in municipalities. The study contributes to the field of human resource management, especially in the context of broader reforms (e.g. Ingraham 2007), as well as to the methodological considerations of evaluating human resource issues within reforms.

The study focuses on the following research questions:

1) How does the quality of working life look like in municipalities that are in the midst of major changes?

2) What factors are related to the variety of the quality of working life in municipalities?

3) How does the present quality of working life compare with the longerterm development in municipalities? 


\section{The context: Reforms in municipalities}

Both international comparative studies and studies conducted in single countries have drawn attention to some major transformations in the contexts in which local governments operate. Denters and Rose (2005: 1-6), for example, identified macro trends and micro/meso trends that condition the operations of local governments in most contemporary democracies. The macro trends they identify are urbanization and globalization and, because their work partly focuses on European countries, also Europeanization. Their micro/meso trends draw attention particularly to the changes in the orientations of citizens towards governments. The ways in which these challenges are met in different countries vary partly because of their historically formed structures and local government traditions.

Studies of local government reforms are manifold. In their review of these studies, Dollery et al. (2008: 2-5) reveal a variation in the foci in terms of, among other things, the number and countries examined; the categories or types of reforms; the determinants of reforms; and the goals, objectives and effects of reforms. The studies range from reforms in single countries to comparisons between various countries. The types of reforms described include functions and finances, powers and organization and management frameworks. Regarding the determinants of the reforms, these studies based on different theoretical approaches highlight influencing factors at different levels, from the perceptions of key-decision makers to institutional, political, economic and ideological factors. As for the goals, Dollery et al. recognize three types of goals that are commonly observed to lie behind the reforms. These are improving municipal governance, enhancing municipal democracy and enhancing multilevel governance, that is, consultation, coordination and cooperation both between municipalities and within local and regional levels as well as between municipal governments and higher tiers of government. An analysis of the effects of the reforms tends to focus on one or more of these goals and objectives. 
There are a number of means by which different countries have striven for a better-performing local government. Amalgamations of municipalities, carried out either voluntarily or obliged by law (e.g. Dafflon 2012), are means often used in reforms. However, also less strict forms of cooperation between municipalities are in use. The reforms may also involve a new share of tasks between central and local government. All these solutions aim to get advantages of economies of scale, with varying actual achievements (e.g. Slack and Bird 2012).

In the international comparisons between local governments, the Nordic countries stand out as their own group. In the Nordic countries, the responsibilities of the municipalities for service provision, including health care, social welfare and education, are exceptionally broad (e.g. Borge and Rattso 2012, Moisio 2012, Naschold 1996: 134; Pollitt and Bouckaert 2000: 42-43). Presently, in all the Nordic countries, local and regional reform processes are under active public discussion. Each of these countries is experiencing both internal and external pressures for structural change and reorganization of services. For example, the aging population generates new demands for services and, on the other hand, the national economy, influenced by global competition, sets boundary conditions for public service provision (Lähteenmäki-Smith 2006, Sandberg 2010).

In Finland, the focus of this study, the project to restructure local government and services is known as the PARAS project. The process is governed by a framework act (The Act on Restructuring Local Government and Services 169/2007) that sets the objectives and means for the desired reform. The objective of the law is outlined to ensure "a viable, well-functioning and cohesive local government structure. Moreover, its aim is to ensure high-quality services for all residents in all parts of the country. The service structure must be comprehensive and economically sustainable and must allow for a cost-effective use of resources."

All Finnish citizens are entitled to get the same basic services irrespective of their place of residence or the size and resources of their own municipality. Local government consists of municipalities and joint municipal authorities. Since there is a big number of small municipalities in Finland that lack the capacity to provide 
the services alone, especially in health care, one way to meet the service provider requirements is to cooperate with other municipalities.

For the implementation of the reform, the act defines especially the following three sets of means: 1) municipal mergers with a view to strengthen local government structure, 2) establishment of partnership areas and increased cooperation between urban areas, and 3) improved operational productivity by making the organization and provision of local government services more efficient and by strengthening the operation prerequisites in urban areas. The assumption behind these means is that the growing size of the municipalities provides benefits; large local authorities and cooperating organizations are able to use their resources more effectively than smaller units and provide better services with the same resources (Meklin 2010, Meklin and Pekola-Sjöblom 2010). In Finland, the municipalities are relatively small in size. As a consequence of political guidance, the number of municipalities has been reduced from 444 to 336 in the period 2004-2012 and the political wish is to diminish their number further substantially.

Slack and Bird (2012: 96) describe the cooperation models between municipalities as follows:

"In Finland, for example, the smallest municipalities in particular have formed partnerships and cooperative arrangements with other municipalities and the private sector to achieve economies of scale (...) The most common form of cooperation is the joint authority in which membership is voluntary except for hospital services and regional councils where each municipality is required to belong by law. Authorities are run by boards that are indirectly elected by member municipalities."

This study is based on the multidisciplinary and multi-actor evaluation programme ARTTU, which was established to evaluate the effects of the PARAS project (Meklin and Pekola-Sjöblom 2010, Evaluation Research Programme ARTTU 2011). The restructuring of both local government and municipal services (PARAS) has been quite a remarkable development initiative in Finland in the 2000s, arousing strong political and public interest. Also, the research 
programme has undergone quite extensive evaluation covering the following perspectives: municipal finances; service provision in social and health care and education; situation of personnel; regional aspects especially in urban areas; what residents think of the available services and what expectations they have about them; gender impact and the linguistic implications of the reform.

The municipalities have gone through a manifold reform process including the launching of new assessment committees, cooperation projects and practices between rivalling municipalities; surveys, training, dissemination and engagement activities among different stakeholders and employees; the introducing of new, complex management models and different kinds of service producing models on the sectorial level. However, in the wholeness of the reform, the main emphasis has been given to economic goals and rationales for change.

On the other hand, the media have raised serious concerns over the level and accessibility of services in the new municipalities as well as related questions about adequate capabilities, recruiting and well-being of employees especially in the health sector professions such as doctors and elderly carers. A common argument by patients' representatives, for example, has been that the working conditions in the centralized services are weak, to say the least.

\section{Theoretical background: The quality of working life}

Quality of Working Life (QWL) is a concept that was rooted in the scientific vocabulary in the early 1970s. The publishing of Quality of Working Life Problems, Prospects and the State of the Art (Davis and Cherns 1975) brought together scholars from different parts of the world to reflect on the concept, its measurement and usage. Since then, a considerable number of writings dealing with the quality of working life, both criticizing and constructively developing the concept (e.g. Martel and Dupuis 2006, Sippola 2011), have been published. 
The concept of QWL has proved out to be difficult to define. In many of the writings, some common ground with the widely used concept of job satisfaction has been brought forth. But also, contrastingly, it has been emphasized that QWL and job satisfaction are different concepts for different purposes. For example, Sirgy et al. (2001: 241-242) summarize the differences found in the literature between the two concepts by arguing that job satisfaction is construed as one of many outcomes of QWL and that QWL does not affect only job satisfaction but also other life domains.

In the lack of a more precise one, Nadler and Lawler (1983: 26) provide a working definition that defines QWL as a way of thinking about people, work and organization. Martel and Dupuis (2006) criticize the definition because, due to its abstractness, it is difficult to operationalize. For our purposes, however, its merits lie in guiding the constituents of QWL. Nadler and Lawler specify their definition further by arguing that its "distinctive elements are 1) a concern about the impact of work on people as well as on organizational effectiveness and 2) the idea of participation in organizational problem-solving and decision-making." In line with the thoughts of Nadler and Lawler we consider that the importance of the concept of QWL lies in its ability to inform us about the individual and organizational impacts of work and to provide tools for organizational corrective or prospective measures.

The history of the concept of QWL is tightly linked with practical development activities in workplaces. Especially the numerous cooperative programmes implemented in the USA have yielded examples of the potential usefulness of the QWL framework (e.g. Lawler 1992: 282-303). As positive results of such programmes, employee wellbeing and satisfaction have increased and, in some cases, also organizational effectiveness and productivity have shown improvements. In the latter objective, however, the results are mixed and often prove out to be difficult to interpret (Walton 1975, Lawler 1982, Prujt 2000).

Since the introduction of the concept of QWL, its operationalization has been under discussion. As a broad concept, OWL has provided us with the challenge of how to cover its different aspects. Typically, it has been defined operationally 
through its components (e.g. Walton 1975, Levine et al. 1984, Mirvis and Lawler 1984, Sippola 2011). Walton (1975), for example, delineates eight categories relating to QWL which all include specific considerations: 1) adequate and fair compensation, 2) safe and healthy working conditions, 3) immediate opportunity to use and develop human capacities, 4) opportunity for continued growth and security, 5) social integration in the work organization, 6) constitutionalism in the work organization, 7) work and total life space, and 8) social relevance of working life.

Defining QWL through these components is not without problems, as Martel and Dupuis (2006), for example, have pointed out. What they see as problematic, on the one hand, is the fact that the listing of components does not provide any information on the relationships between them and, on the other hand, the fact that the definition tends to become moving since the various samples in each study tend to provide different information.

This study uses customary operationalization with versatile information on respondents' experiences and assessments of the different aspects of work and its organizational conditions and determinants. Even though the critique of the measurement approach has brought forth worthy arguments, so far there are no tested and workable alternatives for a survey study to measure QWL. We consider that earlier studies provide a reasonable ground to select the components and specified items for the study.

In this study, the emphasis of QWL lies on the social and psychological relationship between an organization and its employees. This emphasis stems from the focus on municipal restructuration and from the general interest in the question of the vitality of human resource management within structural changes. The attraction of work in the public sector (e.g. Brewer et al. 2012) is a topic that deserves attention because, among other things, it affects attracting and retaining a skilled workforce. Therefore, it should be a major concern for human resource management. The context of the study made it possible to examine how stable or changing a phenomenon QWL is within a far-reaching structural reform and what factors are related to this stability/change. 


\section{Data and methods}

In our study, we employed comprehensive data of the quality of working life and the participation of employees in the PARAS reform in 40 municipalities through two large survey data collected in 2009 and 2011 ( $n=3710$ and $n=4618$ respectively, reply rates $60 \%$ and $52 \%$ ). In addition, we compared these results with previous surveys conducted in 1995, 1999 and 2003 as part of a different research project (“KuntaSuomi 2004”, Nakari 2004).

The municipalities selected represent different sizes and types of Finnish municipalities. The target municipalities represent the Finnish field of local government in regard to different structural reform categories, population size, rural/city categories, linguistic divisions, industrial structure, age structure and geographical location (Jokinen et al. 2011: 18-19). One third of the municipalities included in this study have been formed through municipal mergers, another third consists of cooperation areas and the rest are regular municipalities that have not undergone any major structural reforms.

The survey was directed for employees in the social and health care sector and the education sector, and in 2011, also for employees in the administration sector. As a whole, the occupational distribution follows approximately the same pattern in the survey and the total population in local government Finland. However, in the context of the reform, the boundaries between different sectors are fluid. Related to this, the share of "other" occupations is larger in the sample than in the national statistics. Some of the respondents (e.g. dental care personnel and some specialists) did not consider themselves to belong to any given social and health care category and thus chose the "other" alternative.

The proportion of female respondents was $89 \%$ in 2009 and $85 \%$ in the 2011 survey, while their total share in local government as a whole was $81 \%$ in 2010 (Local government employers 2011). Also the age distribution followed 
approximately the same pattern in the surveys and in the population: the share of under 30 -year-olds was $5-6 \%$ in the surveys (9\% in the population), $18 \%$ in the age group of 30-39 (18\%), 31-32\% in the age group of 40-49 (30\%), 36-37\% in the age group of $50-59(35 \%)$ and $6-7 \%$ in the age group of over 60 (8\%) (ibid.).

Some sources of non-response bias were detected during the research process and corrective actions were taken where possible. In 2009, all 40 municipalities taking part in the Evaluation Programme ARTTU participated also in the survey study; in 2011, two municipalities did not participate due to some other studies going on at the same time. Another thing was that the survey was conducted using paper questionnaires sent by regular mail in 2009 and using a web-based tool in 2011. Hence, the web-based survey caused some bias, leaving especially some social and health sector workers unattainable. Due to this, a second smaller survey $(\mathrm{n}=1,373)$ using paper questionnaires was conducted. To achieve as good reply percentages as possible, at least one reminder message was sent to the nonrespondents in both years, several in the case of the web-based survey.

The analysis proceeds mainly with sum scales of the specified QWL dimensions and the total QWL that sums up all the dimensions (Appendix). QWL consists of five dimensions with several items in each. The dimensions are 1) intrinsic rewards of work, 2) work influence, 3) social openness at workplace, 4) open ways to solve work conflicts, and 5) supervisory work (for alpha coefficients in sum scales, see Appendix). In the first survey round in 2009 it seemed that social and cultural factors might be in a crucial role in the municipality regarding how the reform was felt and handled. Therefore, a new sum variable called social capital was added in the 2011 survey (Appendix). The variable has been used in another study in a municipal context and the measure has been proven to yield consistent results (Oksanen 2009). The index has been developed to cover both cognitive and structural forms of social capital and to include bonding, bridging and linking dimensions of social capital (cf. Szreter and Woolcock 2004; Portes 1998). Participation of employees in the PARAS reform included 15 items, of which three were chosen for closer examination, namely participation to reform, information received and concrete actions seen relating to the reform. Statistical methods will be used here to examine 1) the stability or change of overall QWL, 
2) the stability or change of the QWL differences between municipalities and sectors over the review period, 3) the relationship between QWL and social capital 4) the relationship between the participation in reform and QWL and 5) the predictors of intrinsic rewards and influence at work.

\section{Results}

Since 1995, the quality of working life (QWL) has been studied in municipalities in Finland by employing the same methodology (Nakari 1996: 2004). The variables have been the same; there are only slight differences in the wordings and content of the sum variables between the ARTTU study and the earlier studies. The overall QWL sums up the information covered by five sub-dimensions: open ways to solve work conflicts, work influence, supervisory work, social openness at workplace and intrinsic rewards of work. The correlations between the subdimensions and the total QWL are presented in Table 1. The Cronbach's alpha coefficient which refers to the consistency of the index was in the 2009 sample 0.78, in the 2011 sample 0.79, and in Nakari's (2004) study 0.92. The alpha coefficient in the five dimensions varied between 0.82-0.94 in 2009 and 0.830.94 in 2011.

TABLE 1. Intercorrelations of the sub-dimensions of QWL in 2011

\begin{tabular}{|c|c|c|c|c|c|c|}
\hline & $\begin{array}{c}\text { Work } \\
\text { influence }\end{array}$ & $\begin{array}{c}\text { Social } \\
\text { openness at } \\
\text { workplace }\end{array}$ & $\begin{array}{c}\text { Intrinsic } \\
\text { rewards of } \\
\text { work }\end{array}$ & $\begin{array}{l}\text { Open ways } \\
\text { to solve } \\
\text { work } \\
\text { conflicts }\end{array}$ & $\begin{array}{l}\text { Super- } \\
\text { visory } \\
\text { work }\end{array}$ & $\begin{array}{l}\text { Social } \\
\text { capital }\end{array}$ \\
\hline Work influence & 1,00 &, 377 &, 340 & ,290 & ,309 &, 341 \\
\hline $\begin{array}{l}\text { Social openness } \\
\text { at workplace }\end{array}$ & & 1,00 & ,408 & ,652 & ,663 & ,772 \\
\hline $\begin{array}{l}\text { Intrinsic rewards } \\
\text { of work }\end{array}$ & & & 1,00 & ,302 & ,376 & ,391 \\
\hline $\begin{array}{l}\text { Open ways to } \\
\text { solve work } \\
\text { conflicts }\end{array}$ & & & & 1,00 & ,591 & 659 \\
\hline Supervisory work & & & & & 1,00 & ,780 \\
\hline Social capital & & & & & & 1,00 \\
\hline
\end{tabular}


The results show that QWL is quite a slowly changing phenomenon. The level of the QWL sum-variable (scale 1-5, 5 meaning best quality) varied between 3.373.49 in the period 1995-2011. Also the mutual ranking of the sub-dimensions remains the same, intrinsic rewards of work ranking highest and open ways to solve work conflicts lowest. (Figure 1.)

A high level (> 4) of intrinsic rewards each year as well as the improved values of supervisory work (t-test significant between 2009-2011, p <0.001) are noteworthy.

FIGURE 1. Rank order of the sub-dimensions of QWL in 1995-2011. Means on the scale 1-5; the higher the value, the better

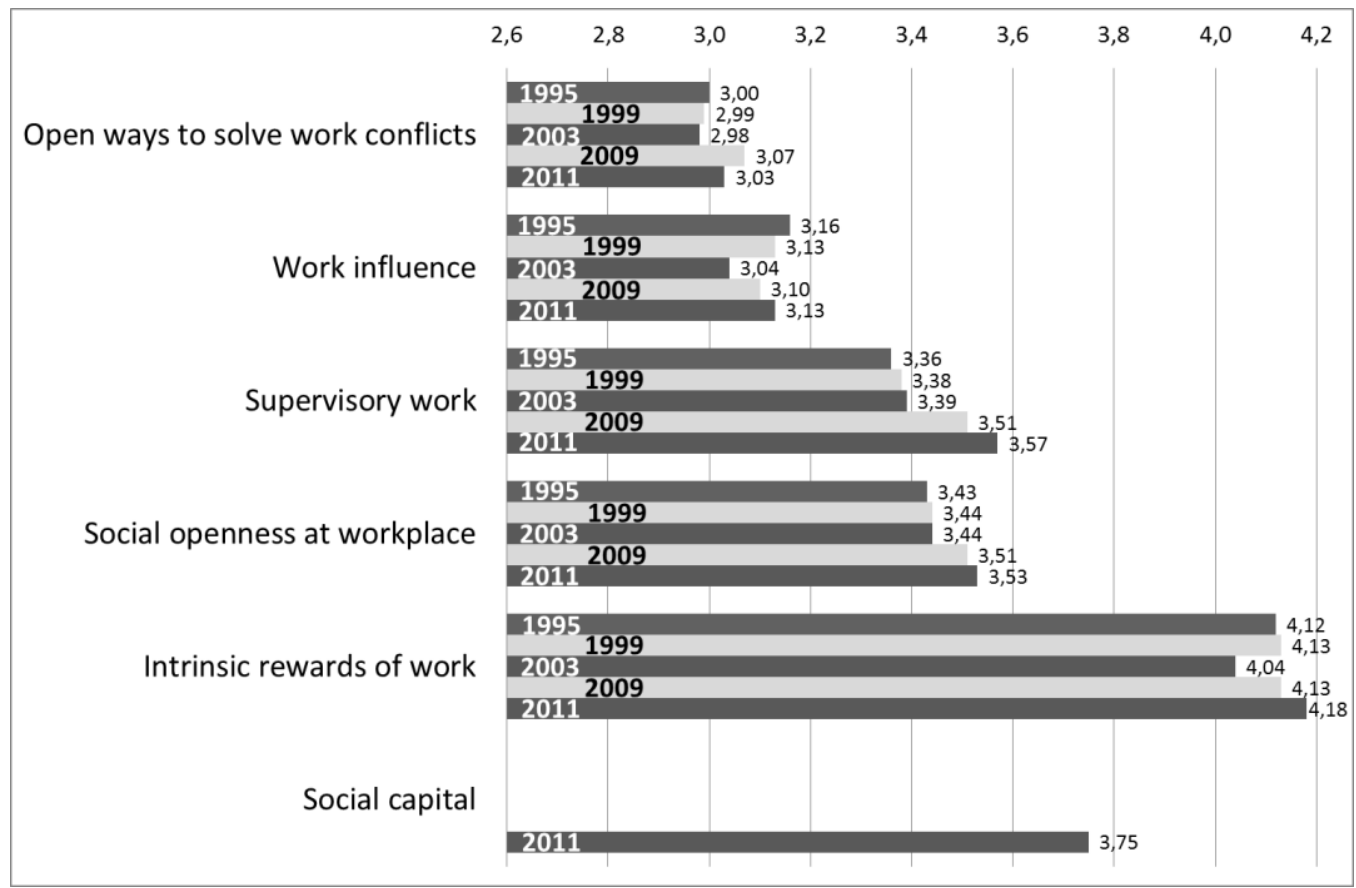

However, behind the stability of the general picture there can be noteworthy variation. Figure 2 illustrates these phenomena by cross-tabulating the municipalities by their ranking in the QWL scale in 2009 and 2011, classifying eight lowest ranking in the category "low", eight highest ranking in the category "high" and the rest in the category "medium". Firstly, QWL differs between municipalities. The scale of variation has diminished from 2009 to 2011 - in 2009 
means 3.14-3.92, standard deviation 0,567; in 2011 respectively $3.27-3.72$ and 0,585 - but there are municipalities both in the lowest- and highest-ranking ends that have secured their positions (see Figure 2).

Overall, the quality of working life was slightly better in 2011 than in 2009, but the difference was not statistically significant (t-test, $\mathrm{p}>0.05$ one-tailed). The change in the level of QWL was statistically significant in seven out of 38 municipalities, of which six had also changed their position in the ranking order.

FIGURE 2. Relative change of the QWL ranking 2009-2011 in municipalities (t-test comparison of 2009-2011 results, * $\mathrm{p}<0.05 ; * * \mathrm{p}<0.01 ; * * * \mathrm{p}<0.001$. Numbers refer to the code names of the municipalities)

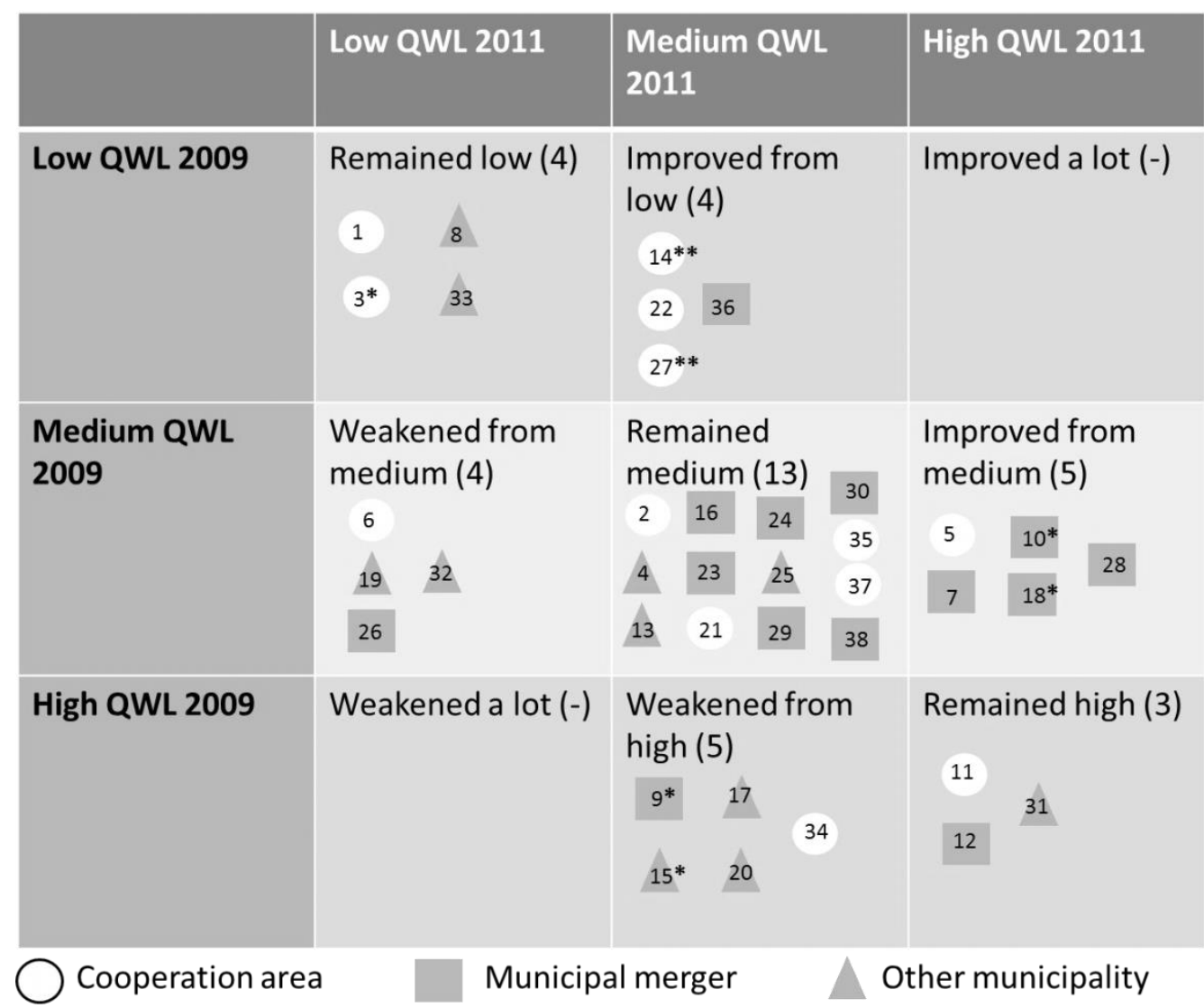

Secondly, the differences between municipalities ranking low and high in QWL are repeated also in all the sub-dimensions of QWL (see Table 2). 
TABLE 2. The total QWL and its different dimensions in 2011. Means of the dimensions on different levels of the total QWL (cutting points: low=25\% quartile, high=75\% quartile)

\begin{tabular}{|l|l|l|l|}
\hline \multirow{2}{*}{ Dimensions } & \multicolumn{3}{|l|}{ Quality of working life, total sum variable } \\
\cline { 2 - 4 } & Low & Medium & High \\
\hline Intrinsic rewards of work & 3.86 & 4.14 & 4.57 \\
\hline Work influence & 2.67 & 3.17 & 3.67 \\
\hline $\begin{array}{l}\text { Social openness at } \\
\text { workplace }\end{array}$ & 3.00 & 3.67 & 4.17 \\
\hline $\begin{array}{l}\text { Open ways to solve work } \\
\text { conflicts }\end{array}$ & 2.50 & 3.00 & 3.75 \\
\hline Supervisory work & 3.00 & 3.70 & 4.20 \\
\hline
\end{tabular}

Thirdly, there are differences between the service functions; also those differences have remained the same in 2009-2011. Both in 2009 and 2011, working with little children was ranked highest and working in health care centres and with elderly people lowest in QWL, and the order between the functions has remained the same since 1995. Some changes in the level of QWL have taken place. Especially the decrease of the level of QWL among health care doctors since 1995 and the increase of it among elderly care workers from 2009 to 2011 are noteworthy (Table 3).

TABLE 3. Quality of working life in different service functions in 1995, 1999, 2003, 2009 and 2011 (Means on the scale 1-5; the higher the value, the better the QWL. 1995: $n=6025$; 1999: $\mathrm{n}=5079 ; 2003: \mathrm{n}=4879 ; 2009: \mathrm{n}=3710 ; 2011: \mathrm{n}=4618)$

\begin{tabular}{|l|l|l|l|l|l|l|}
\hline & 1995 & 1999 & 2003 & 2009 & 2011 & Mean \\
\hline \multicolumn{7}{|l|}{ Social and health care } \\
\hline Sheltered housing for the & 3.37 & 3.36 & 3.33 & 3.24 & 3.41 & 3.34 \\
\hline Health care centre doctor & 3.47 & 3.46 & 3.31 & 3.26 & 3.29 & 3.36 \\
\hline Elderly care & 3.37 & 3.36 & 3.34 & 3.28 & 3.42 & 3.35 \\
\hline Health care centre ward & 3.44 & 3.30 & 3.20 & 3.29 & 3.36 & 3.32 \\
\hline Home nursing & 3.56 & 3.45 & 3.49 & 3.37 & 3.43 & 3.46 \\
\hline
\end{tabular}




\begin{tabular}{|l|l|l|l|l|l|l|}
\hline \multicolumn{2}{|l|}{ Education } & & \\
\hline Upper secondary school & 3.42 & 3.49 & 3.51 & 3.42 & 3.44 & 3.46 \\
\hline Comprehensive school & 3.39 & 3.39 & 3.37 & 3.45 & 3.48 & 3.42 \\
\hline Comprehensive school & 3.66 & 3.67 & 3.59 & 3.64 & 3.63 & 3.64 \\
\hline Day care & 358 & 3.63 & 3.54 & 3.64 & 3.73 & 3.62 \\
\hline
\end{tabular}

Although the quality of working life seems to be relatively stable in nature, it can also show a systematic pattern of change (Figure 2). Regarding structural matters organization form (mergers, cooperation etc.) did not differentiate QWL levels (variance analysis, $\mathrm{p}>0.01$ ). QWL has improved more in smaller than in bigger municipalities, which is visible in the significant difference in t-test $(\mathrm{p}<0.01)$ according to size in 2011. QWL was highest in municipalities where population growth was strong in 2009, but in 2011 such a difference according to the growth variable did not exist.

What is interesting, however, is that eight of the nine municipalities that have improved their ranking in QWL were formed through mergers or established as cooperation municipalities. What is also noteworthy here is that the changes take place in small steps. The relative transfers are all between adjacent categories, not a move from the "low" to the "high", for example.

The different dimensions of QWL in 2011 were examined in the categories of the relative stability/change as applied in Figure 2. All the dimensions point to the same direction; i.e., those municipalities that rank low in the total QWL have lower values in all dimensions than those in the medium category and mediumranked lower values than those in the category "high".

In the 2011 survey a new variable was added that is called here "social capital". The sum index to be used here consists of 8 items (Appendix), the alpha coefficient being 0.89 . The social capital index is highly correlated with the total QWL ( $\mathrm{r}=0.80$ ). As such the correlation is not a surprise since the social aspects of the work communities and supervisory work are included in QWL. Still, the social capital sum scale has a special emphasis that differentiates it from the dimensions covered in the QWL scale. All in all, the average level of social capital is high 
(scale 1-5, mean 3.75). The social capital variable follows the same pattern as the dimensions of QWL, being lowest in the municipalities that rank low and highest in those that rank high in the total QWL (Table 4). Pairwise comparisons of social capital values of those municipalities that have remained the same in the ranking of the QWL to those that have moved to the adjacent category are statistically significant (t-test, $\mathrm{p}<0.01$ ) with the exception of the comparison that remained medium / from medium to low. Noteworthy are the sizable differences in social capital between the municipalities ranking low and high in the total QWL as well as the relatively high values in those municipalities that have improved their positions in the ranking scale and where also QWL has improved in absolute numbers.

TABLE 4. Social capital means in the categories of change in QWL in 2009-2011

\begin{tabular}{|l|c|c|}
\hline Change in QWL & $\mathrm{n}$ & $\begin{array}{c}\text { Social } \\
\text { capital } \\
\text { Mean }\end{array}$ \\
\hline Remained low & 442 & 3.63 \\
\hline From low to medium & 351 & 3.82 \\
\hline From medium to low & 382 & 3.66 \\
\hline Remained medium & 1422 & 3.70 \\
\hline From medium to high & 566 & 3.87 \\
\hline From high to medium & 989 & 3.76 \\
\hline Remained high & 218 & 3.96 \\
\hline
\end{tabular}

The survey also contained questions about how the planning activities had proceeded in the municipalities. We studied more closely the answers given to the questions of whether the respondent considered there had been enough possibilities to participate in the planning of the reform, whether there had been enough information about the reform from the personnel's point of view and whether there had been concrete actions to promote the reform (Table 5). These items were taken for a closer examination since they were positively correlated with QWL, even though the correlations were small $(0.26,0.24$ and 0.18 respectively). 
TABLE 5. Personnel's experienced participation possibilities, information and concrete actions due to the PARAS reform in 2009 and 2011 , \% of respondents

\begin{tabular}{|l|lll|lll|}
\hline & \multicolumn{2}{|l|}{2009} & & & & \\
& & & & & \\
& $\begin{array}{l}\text { Enough } \\
\text { participation } \\
\text { possibilities }\end{array}$ & $\begin{array}{l}\text { Enough } \\
\text { information }\end{array}$ & $\begin{array}{l}\text { Concrete } \\
\text { actions }\end{array}$ & $\begin{array}{l}\text { Enough } \\
\text { participation } \\
\text { possibilities }\end{array}$ & $\begin{array}{l}\text { Enough } \\
\text { information }\end{array}$ & $\begin{array}{l}\text { Concrete } \\
\text { actions }\end{array}$ \\
\hline Agrees & 8.4 & 17.3 & 24.0 & 9.5 & 13.5 & 18.1 \\
Doesn't agree or disagree & 16.4 & 20.1 & 27.6 & 23.0 & 24.3 & 31.3 \\
Disagrees & 54.7 & 46.1 & 20.2 & 48.8 & 40.0 & 18.7 \\
Can't say & 14.5 & 13.0 & 24.4 & 14.8 & 16.8 & 26.5 \\
\hline
\end{tabular}

Participation possibilities in the planning process had increased slightly from 2009 to 2011. This was the case in 31 municipalities out of 38. Answers to the question concerning information about the reform were divided: in 21 municipalities, respondents reported at least slight improvement, while in 14 municipalities they were more critical in 2011 than 2009. Concerning concrete actions, the number of "Can't say" options had remained relatively large, as had the neutral alternative "Doesn't agree or disagree" in both years. A few municipalities could be found where these variables received exceptionally high or low values coupled with values in the same direction in the total QWL.

There is a statistically significant relationship between these variables and QWL (variance analysis, $\mathrm{p}<0.01$ ). The check of interaction effects between these variables and the structural variables (reform type, size, growth) on QWL did not show any significant effects, with the exception of a slight interaction effect of the size of the municipality with information provision. In any case, good information provision contributes to good level of QWL in municipalities of all sizes. The total picture, however, leaves open questions because the aggregate level comparisons of municipalities in these variables of the planning process do not conform fully to the above linear interpretation. It can be also so that the reform proceeds at a different pace in different municipalities and concrete actions that the respondents would recognize as belonging specifically to the PARAS process were not always easy to differentiate from the other ongoing changes. 
Table 6. Predictors of intrinsic rewards and influence at work in regression analysis $(2011 ; \mathrm{N}=4618)$
Dependent variable

\begin{tabular}{|c|c|c|}
\hline Independent variables & $\begin{array}{c}\text { Intrinsic rewards of } \\
\text { work }\end{array}$ & Influence at work \\
\hline & $\beta$ & $\beta$ \\
\hline \multicolumn{3}{|l|}{ Exogenous } \\
\hline Reform type (a1) & -.00 & .01 \\
\hline Countryside (a2) & $-.08 * *$ & -.02 \\
\hline Population size & $-.07 * *$ & $-.08 * *$ \\
\hline Densely populated (a3) & $-.04 *$ & -.02 \\
\hline Population growth & -.03 & .01 \\
\hline \multicolumn{3}{|l|}{ Endogenous } \\
\hline Social capital & $.37 * * *$ & $.30 * * *$ \\
\hline Participation of personnel & $.06 * *$ & $.12 * * *$ \\
\hline Concrete reform actions & $.05 * *$ & -.02 \\
\hline Information of reform & .01 & -.02 \\
\hline \multicolumn{3}{|l|}{ Individual-related } \\
\hline Sex & $.08 * * *$ & $-.10 * * *$ \\
\hline Age & $-.04 * *$ & .01 \\
\hline Physical demands of work (b1) & $.17 * * *$ & $.08 * * *$ \\
\hline Mental demands of work (b2) & $-.10 * * *$ & $.10 * * *$ \\
\hline $\mathrm{R}^{2}$ & .20 & .16 \\
\hline \multicolumn{3}{|c|}{$\begin{array}{l}\beta \text { standardized regression coefficient; } * \mathrm{p}<.05 ; * * \mathrm{p}<.01 ; * * * \mathrm{p}<.001 . \\
\mathrm{a} 1, \mathrm{a} 2 \text {, a3 dummy variables; a1 } 0=\text { no reform, } 1=\text { reform; a } 2 \\
0=\text { countryside,comparing group towns; a3 } 0=\text { densely populated, comparing }\end{array}$} \\
\hline
\end{tabular}

Stepwise analysis, best predictors $(\mathrm{p} \leq 0.01)$. 


\begin{tabular}{lc} 
Independent variable & Intrinsic rewards of work \\
\hline & $\beta$ \\
\hline Social capital & .37 \\
Physical demands of work & .17 \\
Mental demands of work & -.10 \\
Sex & .08 \\
Participation of personnel & .06 \\
Concrete reform actions & .05 \\
Age & -.04 \\
\hline
\end{tabular}

Independent variable

Influence at work

\begin{tabular}{lc}
\hline & $\beta$ \\
\hline Social capital & .29 \\
Participation of personnel & .11 \\
Mental demands of work & .10 \\
Sex & -.10 \\
Physical demands of work & .08 \\
Concrete reform actions & .05 \\
Population size & -.06 \\
\hline
\end{tabular}


Two dimensions of QWL were taken under closer scrutinity: the intrinsic rewards of work and influence at work. Regression analysis was conducted to test factors that explain variation in these two dimensions, covering exogenuous, endogenuous and individual-level factors. Exogenuous factors included structural variables: reform type, size, growth and density of population of the municipalities. Endogenuous factors included social capital, participation of personnel in the planning of the reform, concrete reform actions and communication about the reform. Individual-level factors included the degree of mental and physical strenuousness of work, sex and age. At the first stage of the analysis, the significance of all the above variables as predictors was tested (Table 6). At the next stage, a stepwise analysis was conducted to select the best predictors from the set of the variables, using the significance level $p \leq 0.01$ as the criterion.

In the stepwise analysis, exogenous factors were dropped out of the model as predictors of intrinsic rewards. In explaining influence at work, the size of the municipality remained in the model, which points to the fact that possibilities to influence were assessed to be somewhat better in the smaller municipalities.

Social capital is the best predictor in both intrinsic rewards of work and influence at work, which indicates that the better the level of social capital is, the better the intrinsic rewards and influence at work are, and vice versa. As for intrinsic rewards, a high level of mental strain predicts a high level of intrinsic rewards and the contrary is true in the case of physical strain. Participation possibilities to influence the planning of the reform and notably concrete actions to promote the reform have a positive effect on intrinsic rewards. Younger people considered intrinsic rewards somewhat higher than older people and women more often than men considered their work quite rewarding.

Regarding influence at work, a high level of strain, whether mental or physical, was related to a low level of influence. Men considered their possibilities to influence higher than women. Possibilities to participate in the planning of the reform were positively related to influence at work. 


\section{Discussion}

The study relates to a period of many kinds of structural and organizational changes in the whole municipal sector. The surveys were carried out twice, in 2009 and 2011, and thus gave us a chance to trace possible changes during that time interval. Available comparable data from earlier years, starting from 1995, could be used as a reference point for longer term trends. The focus was on the overall quality of working life (QWL) and on the different dimensions of QWL.

The results can be summarized into three main observations: 1) the relative stability of QWL over the years, 2) the systematic variation in QWL between municipalities and service functions, and 3) certain variation and changes that point to the importance of both the general cultural context where the changes take place and the extent to which change becomes a matter necessitating strategic concern.

Taking into account the potential scale of variation, the observed level of QWL has varied relatively little over the years. A number of changes occurred in the rank order between the municipalities regarding the experienced goodness of QWL during the examination period 2009-2011, but no transfers from the low rank to the high or the other way around; i.e., the changes were in the adjacent categories of the scale. Also the pattern of the sub-dimensions remained the same over the years; i.e., those dimensions that received high scores in one year received them also in another year, and the other way around. The rank order between the service functions also remained the same in 2009-2011. All in all, changes that take place in QWL seem to occur in small steps rather than in striking leaps.

According to the variables of the structural quality of the reform, the results do not show systematic variation in QWL. What is noteworthy, however, is the observation that those municipalities that had improved their relative ranking among the municipalities in QWL as well as their absolute scores in QWL were almost all results of mergers or established cooperation municipalities. This is a result that deserves further consideration. 
Both the relative stability of QWL over the years and the systematic variation between the municipalities and service functions point to the methodological soundness of the approach. The method applied provides consistent results. This conclusion is important from both the methodological and the practical point of view. As reviewed in this article, there has been discussion in the literature of the measuring of QWL since the launching of the concept. The multidimensional measure applied here seems to meet the need of giving consistent results and of being sensitive to the kind of work and conditions in the organization.

International comparative studies have also shown relative stability in the specified features of QWL over the years and clear differences between countries (Fifth European Working Conditions Survey 2010). There is no straightforward way to trace the causes of country differences, since, understandably, also the within-country variation behind the average number is sizable and the surveys do not provide means to control it. However, some institutional factors have been suggested to possibly explain them (Gallie 2003).

We consider that institutional factors might also be behind the differences between the municipalities. By institutional factors we mean, in line with the theorists of what is called new institutionalism (Powell 2008, Brunsson \& Olsen 1990), the rooted rules, beliefs, ways of thinking and cultural norms within a specific municipality context. As an observation from our study, it has come out in workshops organized by the ARTTU evaluation programme with the representatives of the municipalities that structurally very similar municipalities (by size, economic situation) have arrived at quite different organizational solutions with quite different arguments based on the prevailing institutional constellation within the municipality (see also Slack and Bird 2012: 92-102, Meklin and Pekola-Sjöblom 2013: 20, 59-63).

However, in tracing similarities and differences in QWL between the municipalities in the reform context, we should find a way to recognize the social practices behind the results. Exploring social practices with explanatory power is the major challenge that Saunders (2011) specifies for evaluation of broad scale reforms. 
As indicated, there were also some changes to be found behind the overall picture of stability of the QWL level. In the literature there has been discussion of how to interpret changes in people's experiences and attitudes. Golembievski et al. (1976) have characterized changes in terms of alpha, beta and gamma changes, referring by alpha change to absolute quantitative change, by beta change to the respondent's subjective recalibration of the measurement scale and by gamma change to the respondent's reconceptualization of the measured variable (see also Millsap and Hartog, 1988).

The overall stability of QWL over time speaks against the beta and gamma change explanations. The fact that the municipalities that had improved their ranking in the QWL scale are results of mergers or established cooperation municipalities suggests rather that some strategic consideration was devoted to human resource issues in those municipalities. Perhaps also increased inputs for the training of supervisors, which had taken place in most of the municipalities, yielded positive results for QWL in some cases.

Still, in some cases, the gamma change explanation is not without ground either. The comparison of the occupational groups over the years shows changes in the scores of health care doctors and elderly care workers, whose work has been under wide public discussion. The deteriorating trend in the evaluations given by health care centre doctors might reflect something about changed expectations, in addition to concrete conditions of their work. The improved figures by elderly care workers, on the other hand, might reflect concrete improvements in the conditions as a consequence of the demands made in public discussion; wide attention to the issue may also have contributed to the positive feelings of the meaningfulness of the work.

The study took into closer examination two dimensions of QWL, the intrinsic rewards of work and influence at work, and sought explanatory factors for their variation. Structural factors (type of reform, growth perspective of the population and the size of the municipality) do not contribute as such to the level of these variables, with the exception of a minor influence of the size of the municipality. 
The social and cultural situation in the municipality clearly matters when measured by social capital and possibilities to influence the reform. Also individual-related factors (mental and physical strain, age, sex) are linked to these dependent variables.

The intrinsic rewards of work deserve special attention due to their connection to motivation. In some countries, the levels of intrinsic rewards of work were lower in public sector work in comparison to private sector work (Jin 2013), even though also unexamined and stereotypical images prevail on these matters (Rainey and Bozeman 2000). The inferior position of municipal work regarding the intrinsic rewards of work is not the case in Finland (Lehto and Sutela 2009), and also total national figures across the sectors in growth possibilities related to work, for example, are on a relatively high level in international comparisons (Oinas et al. 2012). Such results speak for the need of directing attention to cultural and institutional factors in the public sector motivation studies which have recently gained increased interest (e.g. Brewer et.al. 2012).

Influence at work, for its part, is a crucial moderator of the effects of working conditions on wellbeing (Karasek 1992). Also international monitoring studies have acknowledged its importance as a determinant of the overall quality of working life and have regularly included it into the variable lists to be followed (e.g. Oinas et al. 2012).

In municipal organization, politics and action are interwoven (e.g. Haveri 2008), sometimes even in a conflicting manner. Reforms are driven by political motives and they are not always congruent with the conditions of action in the organizations. It is not rare that reforms look better ex ante than ex post, as Brunsson concludes $(1989,226)$, because the actual reform work tends to reveal the complications and drawbacks that the inspirational talk in favour of the reform does not touch. It may be true that reform often fails to lead to any great change in the way an organization works, as Brunsson (p. 203) states. It may also be that changes are incremental and not immediately detectable, as Kuhlman et al. (2008), for example, found in their study of reforms in German local government, which seems to be the case also in this study. 
There is a need to monitor emerging trends in human resource issues in local governments in both Finland and other countries. The quality of working life is one methodologically valid indicator that provides important information for assessing the attraction of work in municipalities. In any case, the challenge of interpreting the variation found in the results of different time points still remains.

In reform contexts, human resource management strives to ensure that the goals of the reform are achieved by taking various measures and actions. Colley et al. (2012) found that, on the one hand, similar ideas and measures concerning human resource policies have diffused from country to country and, on the other hand, there is a clear need for contextualized understanding and action. The authors of this article sympathize with the views of human resource management as a systemic way to approach personnel issues within a specified environment rather than as a collection of individual HR practices (cf. Colbert 2004). For example, in this study we found that the scores in the assessment of supervisory work had increased. Based on the contextual data within the ARTTU programme, we discovered that municipalities had invested in the training of supervisors. Our assumption is that the impact of individual HR measures (e.g. specialized training) on the overall quality of working life varies according to the social and cultural context of the municipality. Consequently, further research and case studies are needed to corroborate this.

The evaluations of broad scale programmes have found that impact processes tend to be complex and that their effects are often indirect as well as hard to identify and measure. Sanders (2011: 91) defines the question "under what circumstances and why a particular strategy rather than another is likely to yield a positive effect" as the key issue of programme evaluations and suggests an approach that seeks changes in social practice to explain the effect. This advice is worthwhile also in interpreting development trends in the quality of working life. The results of our study of municipal reform indicate that the socio-cultural environment and having the opportunity to participate are of great importance. 


\section{Conclusions}

In quite many countries, local governments are faced with pressures for structural changes and reorganization of their services. This study has dealt with the situation of municipal employees in Finland in the midst of a wide-scale reform planned to respond to the forthcoming challenges of the municipal sector. Within the framework of the reform, in both Finland and many other countries, the personnel have been left in the side role. Still, to achieve the objectives of the reform, they should be in the core role in order to give optimally their adaptive and innovative capacities for the service of the citizens within the new and changing conditions. There is a need for adequate methods to monitor situations of personnel in local government.

The method applied in this study seemed to reflect in context-specific ways the situations in the municipalities and service functions and thus provides an adequate tool for evaluating reforms and organizational changes. The measures of QWL did not show many alarming signs of negative development from the employees' point of view. However, the positive signs were only of a more modest kind, they did not essentially point to any new perspectives for employees. A positive signal was that the intrinsic rewards of work have remained on a relatively high level through the years. Another positive signal was increased satisfaction with supervisory work. It is obvious that rooted rules, beliefs, ways of thinking and cultural norms within a specific municipality context have a preserving function and thus protect employees from continuous changes in their work, which might become strenuous in many ways. The effects of the wide-scale reform on daily work seemed more incremental than radical. In this study, improvements in the supervisory role and a relatively high level of social capital in most of the municipalities suggest as a plausible explanation that they might play a buffering role against the confusion and strains related to the reform.

In the context of local government reforms, the role of human resources is still typically defined as an expense rather than a resource. It is not only wellbeing of personnel, but also gradual changes in the active and contributing role of personnel to organizational changes that should be evaluated before the final 
economical and administrative conclusions about the reform are drawn. In the case of Finland, and other countries as well, conclusions are often rushed under political pressure and they are not always in line with evidence in such issues.

Building new and innovative capacity for work would require deliberate attention to the different aspects of QWL and improvements in the problems observed. In cases in which the reform leaves personnel issues on the side track, it is a challenge for HRM to contribute to the objectives of the reform amidst the tensions created by both preserving and change-requiring powers. Becoming knowledgeable of these tensions and planning the possible individual HR practices in a context-aware manner are the first steps towards this contribution.

\section{References}

Act on Restructuring Local Government and Services 169/2007, Finland.

Borge, L.-E. \& Rattso, J. (2012). Fiscal federalism: International experiences and the Nordic response. In A. Moisio (Ed.), Rethinking Local Government: Essays on Municipal Reform, (pp. 15-42). Helsinki: Government Institute for Economic Research.

Brewer, G.A., Ritz, A. \& Vandenabeele, W. (2012). Introduction to a symposium on public service motivation: An international sampling of research. International Journal of Public Administration, $35(1), 1-4$

Brunsson, N. (1985). The Irrational Organization. Irrationality as a Basis for Organizational Action and Change. Chichester: John Wiley \& Sons.

Brunsson, N. \& Olsen, J.P. (1990). Makten att Reformera. Stockholm: Carlsson.

Colbert, B.A. (2004). The complex resource-based view: Implications for theory and practice in strategic human resource management. Academy of Management Review, 29(3), 341-358.

Colley, L., McCourt, W. \& Waterhouse, J. (2012). Hybrids and contradictions: Human resource management in the contemporary public sector. International Journal of Public Administration, 35(8), 507-512. 
Dafflon, B. (2012). Voluntary amalgamation of local governments: The Swiss debate in the European context. Atlanta, Georgia: Georgia State University, International Center for Public Policy, Working Paper 12-04.

Davis, L.E. \& Cherns, A.B. (Eds.) (1975). The Quality of Working Life. Problems, Prospects and the State of the Art. London: Collier Macmillan Publishers.

Denters, B. \& Rose, L.E. (2005). Comparing Local Governance. Trends and Developments. Basingstoke: Palgrave MacMillan.

Dollery, B.E., Carcea, J., Lesage, E.C. (2008). Local Government Reform. A Comparative Analysis of Advanced Anglo-American Countries. Northampton, MA: Edward Elgar Publishing.

Evaluation Research Programme ARTTU (2011). Retrieved from http://www.localfinland.fi/en/association/research/arttu/Documents/ARTTU-esite_eng_ebook.pdf.

Fifth European Working Conditions Survey (2010). Retrieved from http://www.eurofound.europa.eu/surveys/ewcs/2010/index.htm.

Gallie, D. (2003). The quality of working life: Is Scandinavia different? European Sociological Review, 19(1), 61-79.

Golembievski, R.T., Billingsley, K. \& Yeager, S. (1976). Measuring change and persistence in human affairs: Types of change generated by OD designs. Journal of Applied Behavioral Science, $12,133-157$.

Green, F. (2006). The Paradox of Job Quality in the Affluent Economy. Princeton and Oxford: Princeton University Press.

Halmeenmäki, T. (2010). Kunta-alan eläkepoistuman haasteet ja ratkaisumallit [Retirement attrition in local government: challenges and solutions]. Helsinki: Kuntien eläkevakuutus.

Haveri, A. (2008). Evaluation of change in local governance, Evaluation, 14(2), 141-155.

Ingraham, P.W. (2007). Striving for balance: Reforms in human resource management. In E. Ferlie, L. E. Lynn \& C. Pollitt (eds.), The Oxford Handbook of Public Management, (pp. 521536). Oxford: Oxford University Press.

Jin, M. (2013). Public service motivation: A cross-country study. International Journal of Public Administration, 36(5), 331-343. 
Jokinen, E., Heiskanen, T. \& Nakari, R. (2011). Henkilöstö PARAS-uudistuksessa [Personnel within the PARAS reform]. Helsinki: Kuntaliitto, Acta nro 228.

Karasek, R.A. \& Theorell, T. (1992). Healthy Work: Stress, Productivity and the Reconstruction of Working Life. New York: Basic Books.

Kuhlman, S., Bogumil, J. \& Grohs, S. (2008). Evaluating administrative modernization in German local governments: Success or failure of the "New steering model". Public Administration Review, 68(5), 851-863.

Lawler, E.E. (1982). Increasing worker involvement to enhance organizational effectiveness, In P. S. Goodman and Associates (Eds.), Change in Organizations. New Perspectives on Theory, Research, and Practice, (pp. 280-315). San Francisco, Washington, London: Jossey-Bass Publishers.

Lawler, E.E. (1992). The Ultimate Advantage. Creating High-Involvement Organization. San Francisco: Jossey-Bass Publishers.

Lehto, A-M. \& Sutela, H. (2009). Three Decades of Working Conditions. Findings of Finnish Quality of Work Life Surveys 1977-2008. Helsinki: Statistics Finland.

Levine, M.F., Taylor, J.C. \& Davis, L.E. (1984). Defining quality of working life. Human Relations, 37(1), 81-104.

Local government employers (2011). Kunnalliset palkat ja henkilöstö. [Local government wages and personnel.] Statistical brochure. January 2011.

Lähteenmäki-Smith, K. (2006). Local and Regional Reform Processes in Norden. Acta No. 181, Helsinki: Kuntaliitto.

Martel, J.-P. \& Dupuis, G. (2006). Quality of work life: Theoretical and methodological problems, and presentation of a new model and measuring instrument. Social Indicators Research, 77, 333368.

Meklin, P. (2010). Municipalities measured - Evaluation of the initial situation and development potential of local authorities in the PARAS reform. Summary report on Evaluation Research Programme ARTTU 2010. Evaluation Research Programme ARTTU Studies No. 4. An Acta Plus Publication. Retrieved from http://www.localfinland.fi/en/association/research/arttu/reports/Documents/ARTTU\%20kokoomar aportti\%20eng.pdf. 
Meklin, P. \& Pekola-Sjöblom, M. (2010). Introduction to the research program ARTTU. Retrieved from http://www.localfinland.fi/en/association/research/arttu/Documents/arttu.pdf.

Meklin,P. \& Pekola-Sjöblom, M. (eds.) (2013). Municipalities Measured. Helsinki: Kuntaliitto.

Millsap, R.E. \& Hartog, S.B. (1988). Alpha, beta and gamma change in evaluation research: A structural equation approach. Journal of Applied Psychology, 73(3), 574-584.

Mirvis, P.H. \& Lawler, E.E. (1984). Accounting for the quality of work life. Journal of Occupational Behaviour, 5, 197-212

Moisio, A. (2012). Introduction. In A. Moisio (Ed.), Rethinking Local Government: Essays on Municipal Reform (pp. 1-14). Helsinki: Government Institute for Economic Research.

Nadler, D.A. \& Lawler, E.E. (1983). Quality of work life: Perspectives and directions. Organizational Dynamics, 11(3), 20-30.

Nakari, R. (1996). Työelämän monet kasvot - kuntayhteisö 1995. [The many faces of working life - municipal communities in 1995.] Kunta-Suomi 2004 -tutkimuksia nro 2, Acta No. 63, Helsinki: Suomen Kuntaliitto.

Nakari, R. (2004). Kuntien erilaistuva työelämä. Tutkimus kunnallisista työyhteisöistä 1995-2003. [Differentiating working life in municipalities. A study on municipal work communities 19952003.] KuntaSuomi 2004, Acta No. 170, Helsinki: Suomen Kuntaliitto.

Naschold, F. (1996). New Frontiers in Public Sector Management. Berlin, New York: Walter de Gruyter.

Oinas, T., Anttila, T., Mustosmäki, A. \& Nätti, J. (2012). The Nordic difference: Job quality in Europe 1995-2010. Nordic Journal of Working Life Studies, 2(4), 135-151.

Oksanen, T. (2009). Workplace Social Capital. Annales Universitatis Turkuensis, Series D 876. Turku: University of Turku.

Pollitt, C. \& Bouckaert, G. (2000). Public Management Reform: A Comparative Analysis. Oxford: Oxford University Press.

Portes, A. (1998). Social capital: Its origins and applications in modern sociology. Annual Review of Sociology, 24, 1-24. 
Powell, W.W. (2008). The new institutionalism. In S.R. Clegg \& J. R. Bailey (Eds.), The International Encyclopedia of Organization Studies (pp. 976-979). New York: Sage.

Pruijt, H. (2000). Performance and quality of working life. Journal of Organizational Change Management, 13(4), 389-400.

Rainey, H.G. \& Bozeman, B. (2000). Comparing public and private organizations: Empirical research and the power of the A Priori. Journal of Public Administration Research and Theory, 10(2), 447-469.

Rose, L.E. \& Ståhlberg, K. (2005). The Nordic countries: still the promised land? In B.Denters \& E. Rose (eds.), Comparing Local Governance. Trends and Developments (pp. 83-99). Basingstoke: Palgrave MacMillan.

Sandberg, S. (2010). Lika som bär? Kommunerna in Norden. Finlands kommuntidning 6/2010 Norden bilaga.

Saunders, M. (2011) Capturing effects of interventions, policies and programmes in the European context: A social practice perspective. Evaluation, 17(1), 89-102.

Sippola, M. (2011). Työelämän laadun käsitteen muutos - sisällönanalyysi kansainvälisistä liiketaloustieteen artikkeleista vuosina 1984-2009. [The change of the concept of quality of working life - Content analysis of the articles published in the field of business economics in years 1984-2009.] Hallinnon tutkimus 30(1), 20-36.

Sirgy, M. J., Efraty, D., Siegel, P. \& Lee, D.-J. (2001). A new measure of quality of work life (QWL) based on need satisfaction and spillover theories. Social Indicators Research 55, 241-302.

Slack, E. \& Bird, R.M. (2012). Merging municipalities: Is bigger better? In A. Moisio (Ed.), Rethinking local government: Essays on municipal reform (pp. 83-130). Helsinki: Government Institute for Economic Research.

Szreter, S. \& Woolcock, M. (2004). Health by association? Social capital, social theory, and the political economy of public health. International Journal of Epidemiology, 33, 650-667.

Walton, R.E. (1975). Criteria for quality of working life. In L.E.Davis \& A.B. Cherns (Eds.), The Quality of Working Life, Vol. I (pp. 91-104). New York and London: The Free Press 


\section{Acknowledgements}

We would like to thank the Finnish Paras-ARTTU research programme, the Association of Finnish Local and Regional Authorities and the University of Tampere for cooperation in this research project.

Appendix: Quality of working life $(\mathrm{QWL}$, alfa = .79) sum variables

Intrinsic rewards of work (alpha $=.85)$

K2107 Work develops the worker.

K2105 Work is interesting.

K2106 Work requires me to learn new things.

$\mathrm{K} 2109$ Work is varied.

K2112 One can use one's know-how in work.

K2111 One can achieve one's goals in work.

K2110 Work requires responsibility.

Work influence (alpha $=.83$ )

K1003 On pace of the work.

K1002 On order of your tasks.

K1001 On what is included into your tasks.

K1004 On your working methods.

K1005 On how work is being divided among people.

K1006 On whom you are working with.

Social openness at workplace $($ alpha $=.86)$

K1106 Atmosphere at our workplace is encouraging.

K1107 Tasks at our workplace are well organized.

K1109 Know-how is being appreciated at our workplace.

K1104 Information is being transmitted openly at our workplace.

K1108 There is positive attitude towards changes at our workplace.

K1102 People can really be trusted at our workplace.

Open ways to solve work conflicts (alpha $=.89$ )

K2307 Conflicts are being discussed openly at the workplace and we try to find a solution which benefits all.

K2306 When conflict appears, we try to find a compromise solution which satisfies all.

K2308 When conflict appears, we search for a reasonable solution which is based on expertise.

K2304 Open coming up of conflicts is being encouraged.

Supervisory work (alpha $=.94)$

K2411 My supervisor builds up trust.

K2408 My supervisor supports and encourages me.

K2412 My supervisor acts fair and equal.

K2402 My supervisor is inspiring.

K2410 My supervisor appreciates my know-how.

K2407 My supervisor shares responsibilities in a reasonable way among workers. 
K2403 My supervisor tells openly about all work-related matters.

K2404 My supervisor trusts her workers.

K2409 My supervisor knows my tasks well.

K2406 My supervisor encourages workers to educate themselves and develop in their work.

Separate sum variable:

Social capital (alpha $=.89)$

K2413 Our supervisor treats us with kindness and consideration.

K2414 Our supervisor shows concern for our rights as employees.

K2415 We can trust our supervisor.

K2501 People keep each other informed about work-related issues in the work unit.

K2502 We have a 'we are together' attitude.

K2503 People feel understood and accepted by each other.

K2504 People in the work unit cooperate in order to help develop and apply new ideas

K2505 Do members of the work unit build on each other's ideas in order to achieve the best possible outcome? 